\title{
MIGRACIONES EN LA ANTIGÜEDAD. REFLEXIONES COMPARATIVAS CON SU TRATAMIENTO JURÍDICO EN EL PRESENTE
}

\author{
MIGRATIONS IN THE CLASSICAL ERA. COMPARATIVE REFLECTIONS \\ AND ITS JURIDICAL TREATMENT IN THE PRESENT DAY
}

Carlos Amunátegui Perelló*

\section{INTRODUCCIÓN}

El establecimiento de una economía capitalista supone que los productores no solo orientan su producción hacia el mercado, sino que además tienen la posibilidad de contratar en el mismo los diversos factores de la producción, sean trabajo, capital fijo o circulante. Siguiendo a Polanyi ${ }^{1}$, una economía de mercado se caracteriza específicamente por la acción del mercado como fijador de precios para todos y cada uno de los factores de la producción. El establecimiento de dichos mercados es un proceso lento y angustiante, que altera las estructuras sociales profundamente y que, en muchas ocasiones, crea heridas que difícilmente se sanan a lo largo del tiempo. El reemplazo del modelo productivo familiar por otro de carácter capitalista supone diversas transformaciones sociales y jurídicas para la movilización de los distintos factores de la producción. Así, el

\footnotetext{
Profesor de Derecho Romano de la Pontificia Universidad Católica de Chile. Este artículo es parte del Proyecto Anillo de Investigación Asociativa SOC 1111 "Estudios Histórico-Dogmáticos de Derecho Patrimonial Privado: una mirada a los artículos de los Libros II y IV el Código Civil de Chile". Correo electrónico: camunate@uc.cl.

1 Polanyi, Karl (1976): "La economía como actividad institucionalizada" en PolanyI, Karl, ArensBerg, Conrad y Person, Harry, Comercio y Mercados en los Imperios Antiguos (Barcelona, Labor Universitaria) pp. 289-315.
}

proceso de conversión de determinados tipos de capital fijo, como la tierra, en bienes transables en el mercado, supone la construcción de un derecho de orden abstracto que sea capaz de aplicar a este tipo de bienes las mismas reglas que a los bienes de consumo, como es el caso del derecho de dominio ${ }^{2}$. Otro tanto debemos decir del trabajo, tal vez el factor más difícilmente transformable en mercancía de todos aquellos involucrados en los procesos productivos. La transformación de Roma en el poder dominante de la vasta red de intercambios económicos ${ }^{3}$ que

\footnotetext{
2 Sobre la creación del dominio como concepto jurídico véanse, entre muchos otros: Amunátegui PeRELló, Carlos (2010): “The collective ownership and heredium" in RIDA 57 53-74; Fuenteseca DegeneFFE, Margarita (2004): La formación romana del concepto de propiedad (Madrid, Dykinson); CAPOgrossi Colognesi, Luigi (1969): La struttura della propietà e la formazione dei iura praediorum nell'età repubblicana (Milano, Giuffrè); Capogrossi Colognesi, Luigi (1987: 117-139): "Das Eigentum in Rom vom Ende der patriarchalischen Ordnung bis zur Blütezeit der Sklavereiordnung" in Eigentum Beiträge zu seiner Entwicklung in politischen Gesellschaften. (Weimar, Bohlau) pp. 117-139; CApogrossi Colognesi, Luigi (1988): "Voce propietà" in Enciclopedia del Diritto (Milano, Giuffrè) 37 pp. 160-225, y el ya clásico estudio de Piccinelli, Ferdinando(1980): Dominium est ius utendi et abutendi re sua quatenus iuris ratio patitur (Napoli, Jovene)

3 Sobre el problema de la transformación de Roma en una economía de tipo capitalista véanse: DE MARTino, Francesco (1985): Historia Económica de la Roma Antigua (Madrid, Akal) pp. 83-93.
} 
tuvo por eje el Mediterráneo durante la Antigüedad, supuso la creación de un extenso mercado de trabajadores esclavos ${ }^{4}$, que no de trabajo ${ }^{5}$, donde estos eran sometidos a las reglas de intercambio propias de las mercancías a fin de asegurar su movilización heteróno$\mathrm{ma}^{6}$ y su colaboración dentro de los procesos productivos orientados al intercambio ${ }^{7}$. En este sentido, la Antigüedad optó por someter a los hombres al régimen de propiedad, al igual que al capital fijo, para asegurar la posibilidad de transar de sus esfuerzos productivos en el mercado.

No obstante la enorme extensión de este fenómeno durante la Antigüedad, los ciclos productivos cambiaron de signo y,

\footnotetext{
4 Si bien la esclavitud es bastante anterior al período en estudio, toda vez que parece haber sido introducida ya durante la monarquía etrusca: Franciosi, Gennaro (1959): "Res mancipi e res nec mancipi" in Labeo 5 (1959) 3, p. 375; Franciosi, Gennaro (1992): Famiglia e persone in Roma antica (Torino, Giappichelli), p 206; De Martino, Francesco (1997a): "Intorno all'origine della schiavitù a Roma» in DE Martino F. Diritto economía e società nel mondo romano, (Jovene, Napoli) v. III, pp.82-83; De MARTINo, Francesco (1997b): «Intorno all'origine della schiavitù a Roma" in De Martino F. Diritto economía e società nel mondo romano, (Jovene, Napoli) v. III, pp. 27-57.
}

5 En todo caso, recientemente el estudio del trabajo libre en Roma tardo republicana e imperial parece cobrar mayor importancia e incluso se plantea la posible existencia de un verdadero mercado de trabajo en Roma. En este sentido resultan importantes: HARRIs, William V. (2011a): "Poverty and destitution in the Roman Empire” in Rome's imperial economy (New York, Oxford University Press-Kindle ed.) 1.546-578 y Kehoe, Denis (2012): “Contract labor" in ScheIDEL, Walter (Ed.) Roman Economy (New York, Cambridge) pp. 114-131. La visión más extrema al respecto: Temin, Peter (2013): The roman market economy (Princeton, Princeton University Press) pp. 114-138.

6 Gaudemar, Jean Paul de (1991): El orden y la producción. Nacimiento y formas de la disciplina de fábrica (Madrid, Editorial Trotta) p. 152.

7 Sobre la introducción de la esclavitud en Roma, véase: De Martino (1997b). después de la gran crisis económica, política y social del siglo III, el fenómeno de la esclavitud comienza a disolverse como medio de reclutamiento y movilización de mano de obra para ser reemplazado por otras formas de control de la movilidad de los trabajadores, esencialmente la adscripción a la tierra de los mismos y la creación de formas de vasallaje que impedirán la migración de los hombres hacia las ciudades. Junto con ello, nacerán normas cuyo fin específico será impedir la migración y, así, asegurar la aplicación de los hombres a los procesos productivos a los cuales estaban tradicionalmente vinculados. El objetivo de este trabajo, que todavía se trata de un estudio en fase preliminar, es estudiar dichas normas a fin de establecer paralelos con el presente.

\section{IMPERIO Y MOVILIDAD}

El afianzamiento de la hegemonía romana a lo largo del Mediterráneo trajo como consecuencia una nueva libertad de movimiento para los habitantes libres del Imperio. La seguridad de los mares ${ }^{8}$, la construcción de extensas redes de caminos y la presencia de un control romano sobre los territorios más conflictivos, aseguraron una nueva autonomía de movimientos de la que no se tenía memoria en la Antigüedad. En efecto, el mito de Rómulo fundando Roma como un asilo para refugiados "might have been designed expressly to legitimize of a citizen body based not on birth but on the

\footnotetext{
8 A pesar de la debilidad de la última República respecto a la piratería, debe recalcarse que, luego de las campañas de Pompeyo y, sobre todo, tras la victoria final de Augusto sobre Sexto Pompeyo, la piratería descendió considerablemente, facilitándose enormemente el comercio marítimo. Véase: TARAWACKA, Anna (2009): Romans and Pirates. Legal perspective. (Warszawa, Uniwersytetu Kardynala Stefana Wyszynskiego). pp. 26-46.
} 
desire to become Roman"'. Así, Cicerón, resumiendo el espíritu cosmopolita de la época exclama: Patria est ubicumque est bene (Cic., Tusc. Disp., 5. 108), la patria está donde quiera que se esté bien.

Las calles de Roma eran un hervidero de extranjeros, donde se mezclaban habitantes de todas partes del Imperio atraídos por las oportunidades que la ciudad brindaba. Si bien ocasionalmente se dieron restricciones a la entrada de determinados grupos, se trataba más bien de limitaciones a ideas y cultos exóticos cuyas consecuencias eran, de alguna manera, temidas por los romanos, más no de limitaciones al movimiento migratorio como tal ${ }^{10}$. En efecto, la multiplicación de la población de la ciudad de Roma, desde unos doscientos mil habitantes durante el siglo III a. C. hasta los más de un millón en el último siglo de la República $^{11}$, debe explicarse a través de procesos

\footnotetext{
9 Morley, Neville (2006): "Social Structure and demography” en Rosenstein, Nathan and MorsteinMarx, Robert (Eds), A Companion to the Roman Republic (Oxford, Blackwell-Kindle Edition). 1.5167

10 Tal vez la más famosa de estas limitaciones afectó al culto a Dionisio y la prohibición de las bacanales. El episodio está registrado en Livio 39.18.6 y Valerio Máximo 6.3.7. Véanse al respecto: DülL, Rudolf (1943): "Iudicium Domesticum, Abdicatio und Apoceryxis" in Zeitschrift der Savigny Stiftung 63, pp. 60; Volterra, Edoardo (1995a): «Il preteso tribunale domestico in diritto romano " in Scritti Giuridici. v. II (Napoli, Jovene) p. 120 y Volterra, Edoardo (1995b): " Nuove ricerche sulla conventio in manum " in Scritti Giuridici. v. III (Napoli, Jovene), p. 265; Yaron, Reuven (1962): "Vitae necisque potestas" in Tijdschrift voor Rechtsgeschiedenis 30, p. 243; Watson, Allan (1975): Rome of the XII Tables, Persons and Property (New Jersey, Princeton University Press). p. 37 y Voci, Pasquale (1980): "Storia della patria potestas da Augusto a Diocleziano" in IURA 31 p. 419, entre otros.

11 Para un cálculo de la población de Roma véase: Brunt, Peter (1971): Italian Manpower 225BC-14 $A D$. (Oxford, Oxford University Press).
}

migratorios que terminaron por convertirla en la primera metrópolis de la humanidad.

Luego de las guerras anibálicas, los campos de Italia quedaron prácticamente despoblados ${ }^{12}$. La economía tradicional de agricultura de cereales, cuyo destino eran los mercados de las grandes ciudades, enfrentó imbatible competencia del grano importado desde Sicilia y Egipto, que terminó por arruinar a los pequeños agricultores que subsistían. El resultado fue un proceso de migración campo-ciudad que culminó en un crecimiento urbano desordenado que transformó a Roma en una ciudad de aspecto caótico con algunos de sus montes convertidos en distritos paupérrimos que competirían fácilmente con las peores favelas latinoamericanas del presente.

No obstante, esta corriente migratoria de carácter autónomo no fue la única que experimentó Roma tardo republicana. A contar de la primera guerra púnica (264241 a. C.) Roma se asomó a los grandes mercados de la cuenca del Mediterráneo y su control de la península italiana y las islas que adyacentes a ella (Sicilia, Córcega y Cerdeña) la transformó en la dueña del acceso a los mercados del occidente de dicho mar. Roma, además, emerge del conflicto como la primera potencia naval de la Antigüedad, algo que le permitirá extender su comercio a todos los rincones del mismo. La Segunda Guerra Púnica (218-201 a. C.) tuvo un efecto devastador en los medios de producción dentro de Italia, la cual, tras

\footnotetext{
12 Para un análisis en profundidad del fenómeno véanse: Alfödy, Geda (1984): Historia Social de Roma (Madrid, Alianza) pp. 65-93, De Martino, Francesco (1985) pp. 83-93, Marcone, Arnaldo (1997): Storia dell'agricoltura romana (Roma, Nuova Italia Scientifica) pp. 123-150 y CApogrossi CoLOGNESI, Luigi (2007): Diritto e potere nella storia di Roma (Napoli, Jovene) pp. 185-190.
} 
ser ocupada por veinte años, quedó yerma y despoblada, quedando sus bienes raíces a disposición de una clase de capitalistas que emergió rica gracias a los inmensos botines de guerra obtenidos y que, rápidamente, se destesaurizaron y convirtieron en moneda ${ }^{13}$. En pocas palabras, si la Primera Guerra Púnica puso a Roma en el centro de los mercados del Mediterráneo, la segunda puso a disposición de su clase senatorial y ecuestre inmensos flujos de capital fijo (tierras) y circulante (dinero) para comenzar una expansión capitalista. El modelo productivo exacto aplicado a la producción fue la villa, una nueva unidad productiva dedicada a la agroindustria (esencialmente vinos y aceite) creado por sus vecinos griegos y cartagineses que producía bienes destinados al comercio de larga distancia, en lugar del mercado local ${ }^{14}$.

Es en este contexto que debe entenderse el segundo movimiento migratorio que acompañó al auge de Roma, la migración heterónoma de cientos de miles de esclavos que fueron importados a Italia a fin de aplicar sus esfuerzos a procesos productivos de carácter agroindustrial ${ }^{15}$. Las guerras dejaron tras sí una inmensa cantidad de prisioneros que fueron transformados en esclavos y ofrecidos en los mercados italianos. Más de diez mil trabajadores eran transados

\footnotetext{
13 Sobre la monetarización de la economía italiana, véase Poвjoy, Mark (2006): "Epigraphy and Numismatics" en Rosenstein, Nathan \& Morstein-MarX, Robert, A companion to the Roman Republic (Oxford, Blackwell-Kindle) 1. 1039-1460.

14 De Martino (1985) pp. 95-146.

15 Es casi imposible determinar el número de esclavos en Italia para la República tardía o el Principado. Una buena adivinanza es estimarlos en torno al 20\% de la población. Véase Harris, William V. (2011b): Demography, Geography and the Sources of Roman Slaves in Rome's imperial economy (Oxford, 2011, New York, Kindle ed.) 1.1013-1285.
}

diariamente en el Foro Boario, para ser aplicados a las distintas tareas de producción que las villas requerían. Este impulso migratorio se encontraba amparado por la reificación jurídica de los hombres, que los equiparaba a los demás bienes productivos y que permitía intercambiarlos en los mercados a través de la simple figura del dominio, al igual que cualquier otra mercancía o bien de capital más. Roma, en este sentido, no tuvo un mercado del trabajo, sino de trabajadores, que permitió el desarrollo de una suerte de capitalismo agrario.

Debe destacarse que, no obstante la dureza de la vida de este tipo de trabajador migrante, las rebeliones fueron más bien escasas. Si descontamos algunos episodios aislados ocurridos en Sicilia y la gran rebelión de Espartaco durante la década del setenta del último siglo de la República ${ }^{16}$, las fuentes no mencionan mayores conflictos. Es más, existe una completa indiferencia de parte de la plebe urbana, integrada en su mayor parte por migrantes autónomos, respecto a la condición de los esclavos. Buena parte de dicha falta de solidaridad y pasividad pueden explicarse por la costumbre de los romanos de liberar a los esclavos cuando estos alcanzaban una cierta edad en que sus esfuerzos productivos dejaban de ser económicamente rentables para sus amos ${ }^{17}$. Ya Catón aconseja liberar a los esclavos viejos y esta tendencia alcanza niveles tan altos que incluso se promulgan leyes que intentan limitar el fenómeno ${ }^{18}$. La esperanza de la

\footnotetext{
16 Véase: Guarino, Antonio (1979): Spartaco. Analisi di un mito (Napoli, Liguori editori).

17 Al respecto Temin (2013) pp. 129-152.

18 Así, la lex Fufia Caninia (2. a.C.) limita la cantidad de esclavos que pueden manumitirse por testamento, mientras que la lex Aelia Sentia (4 d. C.) limita los efectos de la manumisión de ciertos esclavos evitando que obtengan la ciudadanía romana, espe-
} 
liberación, bastante real y palpable, se transformó en el corolario de un proceso migratorio exitoso, tanto así que incluso hombres libres extranjeros se vendieron a sí mismos como esclavos con tal de alcanzar la ciudadanía romana ${ }^{19}$. El arquetipo de estos desesperados nos llega en vívidos colores a través de la obra de Petronio, quien describe a Trimalción, un rico liberto que llega a Roma tras venderse a sí mismo. Tan abundante fue el fenómeno que surgió una nueva clase social en Roma, la de los libertos, que se mezcló con la plebe urbana como infraclase de la sociedad.

\section{DECADENCIA DEL CAPITALISMO Y PRESIÓN POR FIJACIÓN}

La sociedad del Principado dependió fuertemente de esta movilidad forzada de hombres, la cual, sin embargo, comienza un declive durante el siglo II de nuestra era, según las guerras victoriosas de Roma, principal fuente de esclavos para sus vastos mercados, comienza a decaer ${ }^{20}$. En efecto, los esclavos que componían su mercado de trabajadores comienzan a hacerse progresivamente más escasos y, consecuentemente, más valiosos. Al mismo tiempo, el agotamiento de las minas de plata de Hispania y el comercio deficitario con los imperios de Oriente provocan una fuerte contracción monetaria al reducirse la cantidad de plata disponible para amonedar. La progresiva baja en la ley de los denarios acuñados por Roma causó un fenómeno inflacionario que

cialmente si los manumitidos son menores de treinta años. Véase Gai, Inst. 1.20.

19 Sobre el problema véase: Volterra (1991): "Manomissione e cittadinanza" in Scritti giuridici v. II. (Napoli, Jovene) pp. 395-416.

20 Véase al respecto: Alfödy (1984) pp. 212-245 y De Martino (1985) pp. 453-474. no se pudo detener ni siquiera con toda la fuerza del imperio ${ }^{21}$. El resultado fue la desmonetarización de buena parte de las relaciones económicas durante la antigüedad tardía y la casi desaparición de la moneda como medio de cambio en toda la mitad occidental del imperio.

La progresiva decadencia económica del Bajo Imperio trajo consigo el declive del capitalismo agrario que había sostenido la economía romana durante siglos. La reducción súbita de la circulación de la moneda eliminó la posibilidad de producir con miras a intercambiar los excedentes en los mercados, mientras que la reducción de la cantidad de esclavos en la sociedad hizo imposible el satisfacer las necesidades de los productores de mano de obra recurriendo al mercado. El sistema capitalista colapsó y los resultados de ello se manifestaron en la crisis económica y social del siglo III.

Tras un largo siglo de desestructuración emergió un nuevo modelo de producción para la cuenca del Mediterráneo. Este ya no tenía el carácter de una economía de mercado $^{22}$, puesto que varios de los factores de producción ya no estaban directamente disponibles para ser adquiridos y la producción muchas veces estaba orientada a la subsistencia. Se basaba ahora en la sujeción del individuo hacia áreas económicas y geográficas determinadas, de las cuales, en lo posible, debía evitarse que escapase. Los esclavos fueron reemplazados por colonos,

${ }^{21}$ Tal vez la iniciativa más interesante al respecto sea el edicto de precios de Diocleciano del año 301, que tasó los valores de una gran cantidad de bienes en un precio oficial. Esta iniciativa fue, naturalmente, un fracaso.

22 Véase Lo Cascio, Elio (2000): "Mercato libero e comercio amministrato in età tardoantica" In Mercanti e política nel mondo Antico (Roma, L'erma di Bretschneider) pp. 307-326. 
ciudadanos pobres que se comprometían a trabajar la tierra de un dueño distante y muchas veces ausente, que simplemente cobraba un canon en especie de las cosechas de estos $^{23}$. Una vez entrado al estatuto de colono, el hombre quedaba vinculado a la tierra y no le era posible desprenderse de ella, pudiendo el dueño de la misma disponer del bien con los colonos incluidos. La sociedad puso fin a un primer ciclo de movilidad representado por el capitalismo agrario de la República tardía y el Principado, para entrar en otro de fijación, propio del imperio tardío. Es en este contexto que, por primera vez, surgen normas jurídicas cuyo fin es controlar las migraciones y, en lo posible, limitarlas.

Fue así como se creó una suerte de estatuto del trabajador que tenía por principal característica evitar su movilidad y fijarlo en el espacio productivo al que estaba adscrito. Así, por ejemplo, en época de Constantino ya se limitaba la posibilidad de los trabajadores agrícolas sujetos a colonato de dejar el predio mientras durasen las labores de recolección ${ }^{24}$, mientras que durante el reinado de Valentiniano y Valente se les prohíbe en absoluto dejar dichas tierras $^{25}$. Poco más adelante, incluso, se establece la obligación de los gobernadores provinciales de retornarlos a sus tierras de origen si es que son sorprendidos fuera

\footnotetext{
23 En sus aspectos económicos, véase: Marcone (1997) pp. 151-174. En sus aspectos jurídicos, en cambio, véase: Sirks, Adriaan Johan Boudewijn (1999): "Ne colonus inscio domino suum alienet peculium." In Mélanges Fritz Strum, v.I. (Liège, Éditions Juridiques de l'Université de Liège) pp. 419430 y (2008) pp. 120-143 y Santilli, Aldo (1999): "Quaedam servitus: il colonus tra legislazione e pensiero giuridico." In Societas-Ius. Munuscula di allievi a Feliciano Serrao (Napoli, Jovene) pp. 275-292.

${ }^{24}$ C 11.48 .1

${ }_{25} \mathrm{C} 11.48 .3$
}

de ellas $^{26}$, prohibiéndose incluirlos en los censos de las ciudades ni otorgarles ningún tipo de privilegio o derecho a residencia en las ciudades donde llegasen debiendo ser inmediatamente deportados a sus lugares de origen ${ }^{27}$. Esto también fue aplicable a otros trabajadores de diversas profesiones que intentaban cambiar de oficio instalándose en las ciudades, donde el anonimato era mayor y la posibilidad de escapar al control de movimiento más amplia. En pocas palabras, la migración queda prohibida para una inmensa masa de trabajadores. Sus normas principales las encontramos a propósito del trabajo agrícola y el colonato, donde se especifica que este tipo de trabajador agrícola

En el entretanto, Constantinopla emergía, producto de una activa política central, como la gran urbe del Imperio, con espacios de libertad y movilidad social que eran raros en el resto del mismo. De ahí que en época de Justiniano, ante el fuerte aumento en la población de la misma, incluso se crease una autoridad especial encargada de controlar las migraciones (año 539), el quaesitor (interrogador), cuyo "encargo es vigilar a la población flotante que llena la ciudad, litigantes llegados de provincias, solicitantes de todas las especies, vagabundos, monjes, mendigos" 28 . Este funcionario debía, en el momento de ingreso a la ciudad, analizar los motivos del viaje y, eventualmente, retornar a los posibles migrantes a sus lugares de origen, para lo cual se utilizaba un procedimiento jurisdiccional. Para trabajar en la ciudad se requería de una autorización que era otorgada por este funcionario, especialmente para profesiones

\footnotetext{
26 C. 11.48 .6

27 C. 11.48 .11

28 Rodríguez López, Rosalía (2007): "Políticas migratorias en Constantinopla (s.IV-s.VI d.C.)” in 54: p. 451.
} 
donde existía merma de trabajadores locales dispuestos a realizarla.

\section{CONCLUSIONES}

Los ciclos económicos influyen en las estructuras sociales y jurídicas, de manera que los cambios en los métodos de producción han de reflejarse alteraciones en el entramado de la comunidad que las experimenta. Durante los últimos doscientos años las sociedades occidentales han ido experimentando a distintos ritmos y con diversos grados de profundidad, la implementación de un sistema de producción de mercado de tipo capitalista que requiere, para su funcionamiento, de la movilización de inmensas masa de recursos, tanto financieros, como de capital fijo y de recursos humanos ${ }^{29}$. Las estrategias utilizadas para perfeccionar dicha movilidad pasan tanto por la creación del concepto moderno de dominio a través del proceso de codificación, como por el establecimiento de mercados laborales de carácter nacional que amparen la movilidad de los trabajadores más allá de las antiguas comarcas donde nacieron y fuera de los vínculos de carácter feudal que caracterizaban las relaciones laborales bajo el Antiguo Régimen.

No obstante la profundidad del fenómeno, la capitalismo actual sigue constreñido por esquemas económicos y políticos basados en el Estado nacional, que intenta poner freno a los procesos migratorios internacionales y al consiguiente establecimiento de un mercado global del trabajo que suponga la libertad de movimientos y de contratación para todos los hombres.

29 PolanyI, Karl (1989): La gran transformación critica del liberalismo económico (Madrid, Las ediciones de La Piqueta).
El establecimiento de autoridades estatales destinadas al establecimiento de trabas a la movilidad a través de la concesión de visados y permisos de trabajo recuerda los esfuerzos por la fijación de la mano de obra realizados durante el Imperio tardío, aunque, curiosamente, los resultados no son la inmovilización de las fuerzas productivas, sino muy por el contrario, su reificación a la manera de la República tardía o el Principado. En efecto, las trabas estatales a la migración rara vez consiguen detenerla, puesto que la necesidad de los hombres de acceder a los lugares donde existan posibilidades económicas para su subsistencia es un aliciente irresistible para la migración: Ubi panis, ibi patria! (donde está el pan, ahí está la patria). Los resultados de las actuales políticas migratorias no son otra cosa que la producción de sujetos mermados en derechos que no pueden interactuar libremente en los mercados del trabajo, sino que se ven obligados a participar de mercados segmen$\operatorname{tados}^{30}$ donde escasamente tienen la consideración de sujetos de derecho, sino que se ven transformados en objeto de relaciones jurídicas.

En este sentido, las políticas migratorias actuales parecen responder a las necesidades del capitalismo privando de derechos -y por tanto reivindicando- al trabajador migrante, acercándonos a un mercado de hombres antes que un mercado del trabajo.

\footnotetext{
30 Piore, Michael J. y SAfford, Sean (2006): Preliminary Thoughts on Identity and Segmentation in Primary Sector Labor Markets. Disponible en: http:// econ-www.mit.edu/files/1135. p. 2; AcHón RodríGuez, Olga (2011): Importando Miseria (Madrid, La Catarata) p. 75-82.
} 
